\title{
A crise da pós-memória e o horizonte das sobrevivências: campos de batalha da memória no Brasil contemporâneo
}

\author{
The post-memory crisis and the horizon of survivals: \\ memory battlegrounds in contemporary Brazil \\ La crisis de la post-memoria y el horizonte de las supervivencias:
campos de batalla de la memoria en el Brasil contemporáneo
}

Roberto Vecchi*

\section{Resumo}

A reflexão que se propõe neste artigo concentra-se sobre o conceito escorregadio de "pós-memória" que surge na década de 1990 em âmbito cultural e não histórico. Tentando localizar os pontos de força e de debilidade que possui, situados em particular no caso brasileiro, a análise se interroga se esta reconfiguração crítica sobre a memória das segundas e sucessivas gerações tem contribuído - ou não - para se inscrever no debate contemporâneo sobre a salvação de memórias em risco. A prática do "desaparecimento forçado" e sua (im)possível herança mnésica para as outras gerações, oferece um ponto extremo de reflexão crítica. Mesmo surgida no contexto da pós-Shoah, a pós-memória encontra aplicações em diferentes contextos críticos como no caso dos autoritarismos militares na América Latina e da ditadura militar brasileira (1964-1985). Depois de uma revisão do debate conceitual, a "pars construens" da reflexão procura verificar se a desmontagem analítica da pós-memória associada à figura das sobrevivências (Pasolini, Didi-Huberman, Warburg, Benjamin) oferece uma nova dimensão crítica com que repensar a transmissão da memória e a economia da herança. Desta revisão, articula-se uma política das sobrevivências que talvez possa reformular, em sua aliança com campos como o da literatura ou das artes, uma outra possível relação com o passado.

Palavras-chave: pós-memória, sobrevivências, ditadura militar, usos do passado.

\section{Abstract}

This article focuses on the slippery concept of "postmemory" that emerged in the 1990s in a cultural rather than historical context. Trying to decipher its points of strength and weakness, situated in particular in the Brazilian case, the analysis questions whether this critical reconfiguration of the memory of the second and successive generations has contributed - or not - to being included in the contemporary debate on saving memories at risk. The practice of "desaparecimento forçado" (forced disappearing) and its (im)possible memory inheritance for other generations offers an extreme point for the critical reflection. Even though it emerged in the post-Shoah context, post-memory finds applications in different critical contexts - as in the case of military authoritarianism in Latin America and the Brazilian military dictatorship (1964-1985). After a review of the conceptual debate, the pars construens of the reflection seeks to verify whether the analytical disassembly of the postmemory, associated with the figure of survivals (see Pasolini, Didi-Huberman, Warburg, Benjamin), may provide a new critical dimension, through which to rethink the transmission of memory and the

\section{Resumen}

La reflexión propuesta en este artículo se centra en el escurridizo concepto de "post-memoria" que surgió en la década de los noventa no en un contexto cultural sino histórico. Al tratar de localizar los puntos de fuerza y debilidad que tiene, particularmente ubicados en el caso brasileño, el análisis se pregunta si esta reconfiguración crítica de la memoria de la segunda y sucesivas generaciones ha contribuido - o no - a insertarse en el debate contemporáneo sobre guardar recuerdos en riesgo. La práctica de la "desaparición forzada" y su (im)posible herencia de la memoria para otras generaciones ofrece un punto extremo de reflexión crítica. Aunque surgió en el contexto postHolocausto, la post-memoria encuentra aplicaciones en diferentes contextos críticos, como en el caso del autoritarismo militar en América Latina y la dictadura militar brasileña (1964-1985). Tras una revisión del debate conceptual, la "pars construens" de la reflexión busca verificar si el desmontaje analítico de la postmemoria asociada a la figura de las supervivencias (Pasolini, Didi-Huberman, Warburg, Benjamin) ofrece una nueva dimensión crítica para repensar la transmisión de la memoria y la economía de la herencia. A partir de esta revisión se articula una

*Università di Bologna, Bolonha,Itália. (Dorcid.org/0000-0001-5982-0810. E-mail: roberto.vecchi@ unibo.it 
economy of inheritance. From this rearticulation, a politics of survivals may perhaps reformulate, in its alliance with fields such as literature or arts, an alternative and possible relationship with the past.

Keywords: post-memory, survivals, military dictatorship, uses of the past. política de supervivencias que quizás reformule, en su alianza con campos como la literatura o las artes, otra y posible relación (viva) con el pasado.

Palabras clave: post-memoria, supervivencias, dictadura militar, usos del pasado.

Haverá e, no caso, qual será o "futuro da memória"? Sobretudo quando a memória é precária ou está em risco? Estas considerações sobre um tema delicado como o "futuro da memória" - predominantemente críticas e com algumas referências a casos do Brasil contemporâneo - trazem muitos problemas, poucas respostas e quase nenhuma solução. Entre aspas, pelo seu caráter problemático e escorregadio, mencionamos a expressão de "pósmemória", uma das figuras mais frequentes com que tentamos entender um pouco mais o "futuro da memória". ${ }^{1}$ Digamos logo que um conceito no mínimo complexo ou até problemático como o de "pós-memória" possui, no entanto, uma qualidade imediata: desvenda uma aporia. A pergunta imediata é: o que acontecerá com a memória, em particular aquela traumática, quando não houver mais os portadores de memória, as testemunhas? $\mathrm{Ou}$, como diz o historiador italiano David Bidussa (2009), o que acontecerá depois "da última testemunha"? Surge assim, já linguisticamente (a palavra composta com um prefixo, pós, sempre enigmático) o problema do depois. E com ele o problema da "pós-memória", desta vez no sentido próprio, ou seja, da transmissão da memória às gerações sucessivas que seguem a geração testemunhal.

\section{As bordas dilaceradas de um conceito: a "pós-memória"}

A "pós-memória" é sempre marcada por um componente de representação, no qual o que o que está em jogo não é mais uma verdade fatual, mas, sobretudo, uma relação afetiva entre o passado e o presente. O círculo familiar é o terreno de disputa em que o passado reivindica seus direitos, às vezes de forma impetuosa, outras vezes, flébil. Enquanto poderoso tipo de "memória protética" (Landsberg, 2004), que surge mais do silêncio do que das palavras, configura-se como "dimensão da recordação intersubjetiva" (Hirsch, 2006, p. 392) ou, adotando a figura proposta por Geoffrey Hartman das "testemunhas adotivas", esse tipo de memória se torna um "testemunho adotivo a posteriori" que instaura uma relação ética com a experiência traumática ou da dor ou as "testemunhas secundárias" (Landsberg, 2004), "as testemunhas das testemunhas" (o que cria uma mise en abysm duplamente aporética).

A "pós-memória", em suma, atesta uma distância que acaba por reafirmar "a natureza diferencial da própria recordação traumática" (Hirsch, 2006, p. 393). Coloca-se entre a continuidade e a ruptura, entre a distância e a proximidade. Entre o silêncio e a intenção de dizer. Daqui o problema se configura como uma questão dramaticamente contemporânea e investe contextos que atravessaram momentos históricos tumultuados como podem ter sido a história latino-americana e brasileira, em particular do último meio século.

O que acontece quando também este tempo, a época da "pós-memória", acabar? A resposta é fácil e trágica: pouco ou nada vai restar dos passados controversos, dos passados que ainda são - o Brasil é um elucidativo exemplo disso - campos de batalha e de disputas ainda em aberto e sem previsão de solução. Depois da "pós-memória", configura-se uma terra vastíssima e desoladora de silêncio. E alguma ruína, ou talvez, pela indecifrabilidade, alguns escombros.

As metáforas da "pós-memória" giram em torno da constelação familiar. É por isso que talvez ela própria se torne uma metáfora conceitual densa, ou seja, o equivalente da herança,

\footnotetext{
${ }^{1}$ A reflexão que constitui este texto resulta em particular do trabalho desenvolvido pelo projeto "Memoirs - Filhos de Império e Pós-memórias Europeias", financiado pelo Conselho Europeu para a Investigação (ERC) no quadro do Horizonte 2020, programa para a investigação e inovação da União Europeia (contrato $n^{\circ}$ 648624), e também graças ao Projeto Dive-In - Iniziativa Dipartimenti di Eccellenza MIUR (L. 232 del 01/12/2016).
} 
uma passagem intergeracional complicada, direta ou indireta, partilhada ou unitária, recebida ou recusada.

Gostaria aqui de lembrar um livro famoso e datado, mas que ainda possui um potencial crítico a meu ver bastante ativo. Espectros de Marx de Jacques Derrida (1994), que oferece um grande arsenal quando se fala da relação entre passado e presente, quando lidamos com heranças, legados, espetros, lutos que não se resolvem.

Derrida neste livro não fala de "pós-memória", mas oferece uma definição extraordinária de herança: "A herança nunca é um dado, é sempre uma tarefa. Que resta diante de nós, incontestavelmente, tanto que, antes ainda de querê-la ou recusá-la, nós somos os seus herdeiros e herdeiros em luto, como todos os herdeiros" (Derrida, 1994, p. 73).

A "pós-memória" é uma figura poderosa, mas, ao mesmo tempo, corresponde a um conceito problemático e escorregadio. O limiar desta reflexão, portanto, aponta para um duplo exercício, sempre necessário para preencher as lacunas ontológicas da normativização do conceito: a "pósmemória" se presta a uma teorização contínua e, também, a uma politização inexausta, que situe o conceito sem perder de vista a dimensão epistemológica da sua precariedade crítica.

Talvez decorra desses limites a desconfiança dos historiadores quanto aos fundamentos da "pós-memória". Não só pela epistemologia duvidosa, já a partir do nome, mas pela origem e natureza predominantemente culturais, literárias, imagéticas do conceito na década de 1990. Também porque as relações entre memória e história nunca estão pacíficas e subentendem filosofias da história que nem sempre os historiadores - sobretudo de certas escolas documentárias - estão dispostos a reconhecer. Como Enzo Traverso observa, ao analisar a relação entre memória e história e os usos políticos do passado, entre os dois campos há sempre um tertium datur, não declarado, nem evidente, que é a consciência histórica que condiciona quem lembra, mas também quem é exposto às variações emocionais e aos sentimentos do passado do próprio tempo e exerce profissionalmente a tarefa do historiador (Traverso, 2006, p. 30). Uma espécie de dimensão fantasmática, mas influente, que desempenha efeitos sobre o dispositivo da memória e a sua vertente historicizável.

Se as contas, então, entre memória e seu "destino" encontram-se grandemente em aberto, é importante considerar os textos que de maneira mais cortante articulam uma crítica à "pósmemória". Isto porque, do ponto de vista do campo conceitual, quanto mais ampla é a discussão sobre um conceito, mais articuladas são suas condições de esboçar uma epistemologia mais forte e menos precária. Inclusive quando estamos a manusear memórias ameaçadas.

Uma contribuição relevante, inclusive pelas preocupações de ordem contextual muito situadas que se depreendem, é aquela da crítica argentina Beatriz Sarlo, no volume Tempo passado: cultura da memória e guinada subjetiva. A crítica que Sarlo dirige à "pós-memória" precisa de um esclarecimento mais articulado, que é parte da arquitetura do volume e já assumido como pressuposto no capítulo em questão dedicado a uma desmontagem da "pós-memória", assim como foi elaborada em Hirsch (1997) e em Hirsch (2001), dois livros conceitualmente débeis, e depois em Young (2000), tornando-a como uma espécie de pseudo conceito, sempre de certo modo problemático.

O que é discutido é, no fundo, um problema que afeta, pelas condições da modernidade, não só a "pós-memória" (que é uma consequência), mas também a salvação tout court da memória, sobretudo depois de uma época em que a vivência pessoal se tornara, pelos processos de mediatização impostos (e a hipertrofia da testemunha), uma condição imprescindível na pseudo recuperação do passado.

$\mathrm{Na}$ crítica do testemunho, em que Sarlo reconstrói a morte crítica e a ressurreição mediatizada do sujeito, há um ponto fulcral de acordo com o qual "quando a narração se separa do corpo, a experiência se separa do seu sentido" (Sarlo, 2007, p. 27). É por isso que visões alternativas, mesmo que caraterizadas por um gesto romântico-messiânico marcado por fortes tensões, como aquelas de Benjamin sobre o eixo experiência e discurso em que os fatos são mitos e a memória se torna uma "instância reconstituidora do passado" (Sarlo, 2007, p. 28), mostram uma insuficiência. Ou um problema. 
A referência a uma perda absoluta da capacidade de narrar a experiência quando o corpo não está em jogo é uma chave evidente que situa a crítica de Sarlo no drama do contexto histórico argentino, mas em geral latino-americano (em que o Brasil desempenhou um papel pioneiro). A aporia do "desaparecimento forçado", que, pela máquina repressiva, produz os desaparecidos e assim o vazio com que repensar um conceito inexoravelmente abstrato como o de "restituição", é o elemento forte da crítica da "pós-memória", como é fácil depreender.

A crítica dirigida tanto às posições de Hirsch (1997) como às de Young (2000) dedicadas à arte e à arquitetura comemorativas contemporâneas, ambas referidas à Shoah, liquida a "pósmemória" como "um gesto teórico mais amplo do que o necessário" (Sarlo, 2007, p. 95), sobretudo localiza os seus elementos constitutivos - o caráter vicário, o vacuum, o aberto, o fragmentário etc. - num lugar problemático, porque, mais do que caraterizar uma especificidade do conceito (Sarlo, 2007, p. 102), são a confirmação de que a rememoração opera sobre algo que não está presente, por isso a fragmentação de seus vestígios é inelutável, pertencendo não à "pós-memória", mas a um universo mais geral e generalizável.

O que se critica, em suma, é o idealismo presente nas codificações fundadoras da "pósmemória", que seriam insuficientes para dar fundamento a um conceito efetivo que se expõe, pela sua debilidade, ao risco de fetichizações banalizadoras de um passado, pelo contrário, completamente perdido, porque o seu corpo foi eliminado, efetiva e não metaforicamente.

Apesar de existirem outros projetos que chegam a um entendimento do passado pondo-se no lugar do ausente (que é a tarefa política implicada pelo trágico dever da memória de Sarlo), o que resta das considerações sobre a herança familiar entre pais e filhos é que, de acordo com a crítica argentina: "não há pós memória e sim formas de memória que não podem ser atribuídas diretamente a uma divisão simples entre memória dos que viveram os fatos e memória dos que são seus filhos. E, admitindo também o diferencial da experiência que distingue a geração testemunhal daquela seguinte, a conclusão é perentória: “todo passado seria abordável somente por um exercício de pós-memória" (Sarlo, 2007, p. 113).

\section{A difícil tarefa dos herdeiros: os tempos da memória traumática no Brasil}

As inscrições da memória e da "pós-memória" nas questões críticas da memória não são redutoras, mas abrem o campo a um potencial crítico extremamente relevante: a memória deve ser entendida não na sua dimensão individual, de recordação, mas naquela coletiva e pública. Política, portanto. O que expõe de imediato o problema sociológico da "pós-memória" que deve sempre ser pensado: a sua contextualização intersubjetiva complexa entre a esfera privada e o espaço público. E a referência final do capítulo ao caso dos desaparecidos mostra a dobra da "pós-memória", o seu dualismo irredutível e "trágico": ser um efeito do discurso sobre o passado e ser também uma relação com os materiais da reconstituição, de uma restituição no entanto impossível, quando o corpo desta memória foi já totalmente destruído, o que impede o instituto jurídico da restitutio ad integrum. Que não apaga, no entanto - até dilata -, os problemas da memória da catástrofe - da catástrofe identitária do desaparecimento forçado que ocorreu (Gatti, 2008, p. 43).

No Brasil, as preocupações sobre a herança das memórias traumáticas adensaram-se em algumas épocas particulares do período pós-autoritário e não só. Num repertório muito sumário, em uma situação híbrida entre memória e "pós-memória" (mas em que o problema da transmissão torna-se evidente), temos um importante curta-metragem em preto e branco, 15 filhos, codirigido por Maria Oliveira e Marta Nehring (1996), duas filhas dos anos de chumbo, que reúne amostras significativas, induzindo uma reflexão sobre a memória e sua possível transmissão. O curta brasileiro atesta como a teia memorial se constrói a partir de um forte grau de subjetividade que procura preencher todas as falhas, inúmeras, da reconstrução. A sequência de depoimentos funciona na verdade como sequência de imagens faladas que se amalgama com rastros fotográficos. Emergem ícones da dor e do trabalho da perda, que se assumem como disfarces, como fetiches de uma restituição impossível: a violência simbólica de uma vistoria da polícia na pipoca da menina, filha do preso político, o indizível que se expõe, nos silêncios ou na fala esburacada pela emoção renovada, apesar da distância temporal dos traumas relatados. 
Ao lado da morfologia dupla que marca esses exemplos de "pós-memória", efeito do discurso e, ao mesmo tempo, relação com os materiais residuários (fotos, imagens, lembranças) pelos quais se tenta a reconstituição, em que as perdas são não tanto falhas da memória, mas produto da economia da destruição operada pelo regime (Sarlo, 2007, p. 113), impressiona um aspecto menos evidente do documentário: o que parece monólogo dos filhos é na verdade - percebe-se pelos ruídos de fundo - o diálogo entre uma segunda geração de vítimas que procura, portanto, já uma sua reestruturação comunitária.

A rigor temos exemplos de relatos antigos da segunda geração (dotada no entanto de experiência trágica, portanto fora de uma categorização restrita de "pós-memória") sobre a época autoritária quando ainda não se tinha esgotado o ciclo como, no campo literário, Feliz ano velho, de Marcelo Rubens Paiva (1984), que, pelo modo que recompõe vivencialmente a fratura entre corpo biológico e corpo político, constitui, no entanto, uma exceção, mais do que um exemplo nesse território. Acentos elegíacos, leveza do trato, mas também os problemas críticos de vasta magnitude, estão já todos expostos de modo nítido no filme de Cao Hamburger, $O$ ano em que meus pais saíram de férias (2006), longa-metragem sobre o registo do trauma da clandestinidade, da tortura, do desaparecimento, da morte do pai e do retorno da mãe, por parte de um menino, no meio de uma acumulação de temas que o filme pressupõe: a vida e os valores da comunidade judaica do bairro do Bom Retiro de São Paulo, o clima de euforia artificial da Copa do Mundo de 1970.

São só alguns exemplos exíguos - o repertório poderia ser bastante mais amplo - que mostram como a preocupação explícita ou latente para o depois da memória experiencial surge, no mínimo, muito misturada com outros componentes memoriais que podem pôr em discussão ou até ameaçar, de fato, como obstrução, o trabalho de uma memória mais supostamente "literal".

A "pós-memória", no entanto, permanece sempre uma categoria precária. Um dos textos principais de Hirsch é ligado à centralidade sobrevivente das imagens: o capítulo "Surviving images: Holocaust Photographs and the Work of Postmemory", presente no volume The Generation of Postmemory (2012), sobretudo porque evidencia a fragilidade da "pós-memória" pelo duplo elo que a caracteriza: a dependência da transmissão da memória das imagens por um lado e a insuficiência das mesmas imagens pelo outro.

É também outro elemento por evidenciar o traço crucial, eu diria ontológico, da sobrevivência como elemento distintivo da categoria "frágil" da "pós-memória", porque, é a hipótese que aqui se esboça, as "sobrevivências" podem realmente levar para um rearme efetivo do conceito.

De certo modo, o texto de Hirsch é um simétrico oposto do texto de Sarlo. Sobre as imagens do genocídio - escassas, repetidas, saturadas - o que emerge é um limite que leva a autora a analisar o funcionamento destas imagens, derivando delas algumas metáforas da memória e da "pósmemória". Vale a pena evidenciar a ideia de que a "pós-memória" é um trabalho, uma obra, o que é interessante pelas implicações que isso pode ter em conexão com o luto ou a melancolia.

E sobre as imagens, vale a pena lembrar um texto esquecido de Primo Levi (1991), uma apresentação (póstuma) de uma exposição fotográfica "Rivistando i campi" (Trieste, 1987), em que potências e limites da "pós-memória" (mesmo antes da sua emersão) são lançadas: as imagens, mais do que as palavras que se perdem na negatividade do indizível, fora de uma linguagem localizada, forma paradoxal da mimese, se podem tornar efetivamente "o melhor esperanto", uma língua universal. ${ }^{2}$

No entanto, apesar da exegese minuciosa das imagens recursivas, o que se afirma com Hirsch como prioridade é a "natureza textual" da "pós-memória" (Hirsch, 2006, p. 393). Não é por acaso que um núcleo do seu ensaio é um conto, um conto sobre uma fotografia, mas sempre um texto, "Traccia" (em português, "Rastro") de Frammenti di tempo, da escritora polaca-

\footnotetext{
2 "Uma imagem, considerando a mesma superfície, 'conta' vinte, cem vezes mais do que a página escrita, e também é acessível a todos, mesmo aos analfabetos, também aos estrangeiros; é o melhor esperanto” (Levi, 1991, p. 6, tradução nossa).
} 
israelense Ida Fink (2002). É um conto "aforístico", enxuto, essencial, mas que funciona como uma "metaimagem", o que serve para a autora estudar "o status privilegiado da fotografia como suporte da 'pós-memória'" (Hirsch, 2006, p. 394).

Aqui surge provavelmente um traço ontológico da memória mediada e intergeracional. Em particular, percebe-se, pelo menos em hipótese, o que poderá acontecer depois da "pósmemória". Se é difícil distinguir uma idade da "pós-memória", provavelmente a nossa, esta ocorreria num trânsito (em curso) de uma responsabilidade da escuta (da voz, da palavra da testemunha) para um outro tipo de responsabilidade: a responsabilidade do olhar. Da leitura e da visão. Não muda a combinação que materializa a memória, a solidariedade entre imagem e palavra, mas a desloca para a capacidade de ver, de interpretar uma obra em que emergem os resíduos negociados afetivamente do passado. É assim que podemos definir a especialização da memória que chamamos - por convenção, moda, hábito e não sem limites - "pós-memória".

É na tensão entre imagem e texto que surge um aspecto fundador da "pós-memória", que sempre se baseia em insuficiências (de informação, de inteligibilidade, de meio etc.). Já Walter Benjamin (1962) tinha detectado o caráter político da fotografia na relação entre a imagem e o texto (a legenda). Hirsch, assumindo a crítica da descrição de uma imagem, com as inúmeras

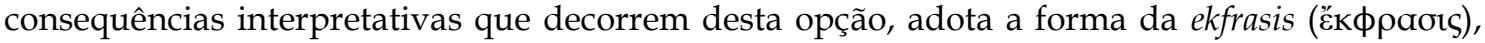
que indica a descrição discursiva de uma imagem (na antiguidade, uma estátua ou um desenho) que acaba por significar, na economia da "pós-memória", a discursividade - subjetiva ou, como se supõe, intersubjetiva - da transmissão do passado.

Esse aspecto e o conto de Ida Fink (2002) induzem a repensar produtivamente o conceito de rastro, a sua condição em absoluto dual, como correlato da representação não homogênea, mas fragmentária, que o transcreve constantemente num horizonte que o torna, assim como a lembrança para a memória, intransitivo e irredutível. O rastro então tem um duplo modo: ou em contato com um real despedaçado que, porém, não se simboliza e perdeu a referência ao todo de que fazia parte, ou, no outro caso, pode manter uma conexão - que pode ser, na memória, pelo elo físico, originária da dor, do evento corpóreo - com uma memória intersubjetiva, com uma sua força paradigmática, de metáfora viva da experiência que se pode assim transmitir.

Hirsch (2006, p. 390-401) atribui múltiplas funções que se acrescentam ao significado mais imediato da "pós-memória" - considerada uma memória "poderosa" porque mediada pela representação e não pela reevocação - como aquela de "reabrir de novo o túmulo" e entender assim "o que as imagens revelam e ao mesmo tempo ocultam à vista".

Tal posição reativa o papel da experiência do intérprete - do "tradutor" - perante as imagens, os rastros que por si não chegam a significar, mas precisam sempre, por assim dizer, de um suplemento para significar. Não é por acaso que a fotografia é lida na sua condição temporal dualista, numa linha que aproxima as reflexões de Barthes e de Sontag: "o encontro com a fotografia é o encontro com dois presentes, um dos quais, já passado, pode ser ressuscitado no ato de olhar" (Hirsch, 2006, p. 403).

Na "pós-memória" - como nas autobiografias no campo literário, se quisermos encontrar um termo de comparação - em suma, o problema não é discriminar o falso do verdadeiro. Trata-se em ambos os casos sempre de representações que funcionam como narrativas ou textos.

O que prevalece é sempre uma abordagem discursiva (crítica, no caso das imagens que, como sabemos, não são um objeto mimético e é sempre oportuno lembrar uma observação de Sartre a este respeito: "a imagem não é uma coisa, mas um ato" (Sartre apud Didi Huberman, 2005, p. 71), como se a atenção meta-mnésica, de reflexão sobre a memória, acompanhasse e se misturasse com a recolha das memórias.

Sobretudo, mostra o aspecto relevante da "pós-memória": a análise da sua produção põe em primeiro plano o papel do olhar, do espectador ou do leitor destas memórias (que mostra uma estratigrafia metodológica na tarefa do tradutor). A "pós-memória" subsistirá - além da sua atual produção - e funcionará se associada a um ato exegético, a um horizonte de receção. Assim talvez possa sobreviver. 


\section{Sobreviver ao passado: restos e sobrevivências}

Contudo, é possível considerar citável um passado que se funda sempre sobre uma provável ou subjetiva errata, uma citação, em suma, sem garantias de factibilidade? Aqui é produtivo não perder de vista a testemunha, e considerar um dado que é comum a muitos pensamentos sobre a "pós- memória": sempre nos referindo às "surviving images" de Hirsch, o elo comum é aquele da "sobrevivência" em toda a expansão semântica do termo, não só pelo aspeto morfológico do termo que o subtrai ao domínio exclusivo da experiência. E implica outro termo, de certo modo messiânico, projetado para o futuro, que é "resto" (Agamben, 2000).

Como observa Hirsch sobre as fotos dos sobreviventes:

Resistem ao trabalho do luto [...]. Elas não podem ser redimidas pela ironia, discernimento ou compreensão. Só podem ser confrontadas repetidamente, com a mesma dor, a mesma incompreensão, a mesma distorção do olhar, a mesma mortificação. E assim, na sua repetição, não representam mais o genocídio nazista, provocam o efeito traumático que esta história teve sobre todos aqueles que cresceram sob a sua sombra (Hirsch, 2012, p. 28, tradução nossa).

É por considerar também que sobrevivente é uma das etimologias da palavra testemunha: que decorre do latim superstes e significa: quem sobrevive a uma experiência e, portanto, pode testemunhá-la (Agamben, 1998, p. 15).

No quadro instável, às vezes trágico, dos problemas da transferência da memória, em particular, traumática, as sobrevivências conceitualizadas talvez possam proporcionar uma pars construens aos imensos problemas da salvação dos passados em risco. E também abrir uma possibilidade interpretativa à vasta produção (refiro-me em particular à literatura, mas a interpretação se poderia estender a outras formas de arte) que hoje, no Brasil, aborda o tema da memória dos anos da ditadura através do olhar das gerações de transição (que tiveram só uma experiência parcial do passado), das segundas (ou até terceiras) gerações, em um contexto negativo para este exercício sobre o passado, atravessado pela nostalgia autoritária de uma fatia significativa e hoje empoderada da opinião pública brasileira.

Uma figura que talvez possa ir além das muitas aporias da "pós-memória" é a das sobrevivências - o testemunho possível - de algo que deliberadamente foi destruído para não deixar rastros (entram nesse "patrimônio de sofrimento" - na definição de Aby Warburg (apud Assmann, 2002, p. 411) - casos como o da Shoah ou do desaparecimento forçado na América Latina, as guerras e as violências coloniais, mas também a destruição da experiência como limiar de construção da nossa modernidade). Mas os rastros, inclusive residuários ou até ausentes, são um apego direto ao passado, diferentemente da "pós-memória", cuja relação com a cena traumática é substancialmente sempre intermediada. São esses contextos de memória em risco alguns casos em que a "destruição sem ruínas" (Wajcman, 1998, p. 23) é a forma extrema que impede qualquer restituição.

No caso das memórias em risco, como no caso das histórias dominadas, dos grupos sociais "subalternos", todo sinal é precioso porque permite reformular de modo alternativo uma imagem do passado. É uma consideração dos Quaderni de Antonio Gramsci (1975, p. 2284). Mesmo que precária, incompleta e débil, a "pós-memória" é a sanção da possibilidade de transmissão do passado, da sobrevivência do passado contra a ameaça de extinção.

Nesse quadro, a metáfora dos "vaga-lumes" que Pier Paolo Pasolini inscreveu num famoso artigo ("L'articolo delle lucciole. Il vuoto del potere in Italia", de 1975, depois reunido no Scritti corsari, 2020, p. 162-169) e que Georges Didi-Huberman (2010) elaborou como "política de sobrevivência" (Survivance de lucioles), é proveitosa. Pasolini, constatando que os vaga-lumes um objeto, mas também uma metáfora polivalente e com muitas raízes semânticas - estão desaparecendo, que a noite não se ilumina mais por suas faíscas, pretende denunciar o "genocídio cultural" provocado pelo novo fascismo - uma reestruturação do velho - na luz ofuscante da investida do consumismo num país - a Itália - que apaga qualquer diferença, qualquer rastro (os vaga-lumes justamente). O caráter mais evidente dessa fascistização é a erosão da experiência e da língua. 
Mas, como acreditar na morte das sobrevivências, pergunta-se Didi-Huberman, pensando num paradoxo que não é só linguístico: como é possível extinguir as sobrevivências? A partir dali, formula uma política das sobrevivências que se articula com base em uma política das imagens, "imagens no limiar do desaparecimento, sempre movidas pela urgência da fuga, sempre próximas daqueles que, para realizar seu projeto, se escondiam na noite e tentavam o impossível, correndo risco de vida" (Didi-Huberman, 2010, p. 41).

Essa visão deriva em particular da aproximação da obra de Aby Warburg, a que DidiHuberman (2006) dedica um amplo estudo: "L'immagine insepolta", que tinha já refletido sobre a abertura da ideia de história por um tempo outro, justamente de "sobrevivência" (Nachleben) das formas antigas. Essa política das imagens que, apesar de tudo, sobrevivem e se inscrevem com seu tempo complexo e suas forças inesperadas no presente, também decorre de uma frase de Pascal que Benjamin resgata e remete para o nosso tema da "herança": "ninguém morre tão pobre que não deixe nada como legado" (Benjamin, 1962, p. 263), ${ }^{3}$ o que mostra a projeção política de um "saber vaga-lume", como o chama Didi Huberman (2010, p. 82), portador de um tempo complexo em que as suas imagens residuárias ("imagens vaga-lumes") são, ao mesmo tempo, testemunho do passado e o relâmpago benjaminiano, antecipador do "não ainda". Possuem mais a inconsistência do sonho do que a consistência do "real". Por isso são assimiláveis a um gesto de transmissão da memória, a partir de uma trama tão heterogênea, de sobrevivências residuárias amalgamadas com outros rastros e funcionando como outras ficções. A ideia, portanto, é pensar uma política das sobrevivências como base para ir além dos impasses da "pós-memória" - que é também uma política do testemunho e da sua possibilidade de transmissão no esgotamento dos efeitos da experiência e da referência.

Dos limites e das impotências da "pós-memória" então, pode-se pensar, inclusive operacionalmente, que a transmissão da memória, em particular traumática, concentra-se em uma recolha de sobrevivências misturadas e inseparáveis das formas em que se incrustam - um "antigo presente" que conjuga tempos diferentes. É oportuno assinalar que a sua natureza não é singular, mas deve ser pensada de uma maneira mais aberta.

Existe uma conexão fecunda - e não só linguística - entre "pós-memória" e a condição do póstumo, na sua etimologia tardia que remete para o verbo sobreviver e que permite entender o papel construtivo e menos vago das sobrevivências. Póstumo como conceito aponta sempre para um suplemento, um depois, um além em que algo sobrevive e também, no marco do fim, se dá uma continuidade, uma herança (Ferroni, 1996, p. 16). Uma continuidade no fragmentário, uma não coincidência de algo de qualquer modo inconcluso, de não acabado. Por isso no póstumo há um resto que persiste culturalmente "vivo-morto" na dimensão posterior, no depois, nas sobrevivências.

Isso desvenda uma conexão forte do campo referível às sobrevivências com a dimensão da morte (morte da testemunha familiar da geração anterior); esta modifica e complica o problema da herança, que transcende do circuito da comunicação intersubjetiva para afundar num espaço de interpretação ainda mais lacunoso e fragmentário, cuja responsabilidade cabe sempre ao portador da memória transmitida e ao seu interlocutor/tradutor.

A configuração muda e se altera com a morte da testemunha a que se relaciona o portador da memória secundária, aquela que chamamos - com todas as ressalvas expressas - "pósmemória". O instante da morte modifica seu estatuto porque atualiza e reinstitui o perfil da herança (que se torna contemporânea) na memória póstuma do sobrevivente que assume "adota"-, assim, a responsabilidade da memória alheia e própria. A exegese do passado, da experiência intransitiva do outro, as sobrevivências que sobram, acabam assim nas espirais de uma indecidibilidade que só a trama literária ou a força da imagem podem - literal e literariamente - "representar".

Podemos assim voltar, ainda que pontualmente, ao contexto do Brasil em que a constelação da transmissão da memória pode ser repensada substancialmente pelo paradigma - certamente

\footnotetext{
${ }^{3}$ Ver também Didi-Huberman (2010, p. 80).
} 
débil, mas em um quadro bastante precário - das sobrevivências. Como se observou acima, os tempos históricos, referidos por exemplo ao contexto da ditadura militar, são voltados para uma prática de mnemocídio em relação as memórias "inconvenientes" do passado autoritário. A Comissão Nacional da Verdade, cuja função foi essencial e significativa para salvar passados ameaçados, não conseguiu, no entanto, tornar as memórias frágeis dos anos da ditadura, na perspectiva das vítimas, memórias fortes (Traverso, 2006, p. 51). As memórias das vítimas foram um tema de campanha eleitoral de 2018 e uma diretriz de ação do governo que se seguiu: a ideologização e polarização do passado representam um obstáculo enorme para a construção de uma memória pública e de reconciliação. No entanto, no plano cultural, o passado ameaçado se tornou um tópico central, pelo menos na última década. E com uma tônica diferente. O que foi abordado é o problema da transferência da memória de uma geração para outra, no momento em que os portadores de experiência estão desaparecendo. Isto ocorre como tema, mas também como prática meta-literária, ou seja, a escrita que se interroga sobre o modo com que ela própria, a escrita, pode salvar passados em risco. Livros como Azul corvo, de Adriana Lisboa (2010), ou Palavras cruzadas, de Guiomar de Grammont (2015), de modo diferente, abordam o tema (impossível e trágico) das extinções da guerrilha de Araguaia na perspectiva da construção de uma memória para a geração mais nova (Vecchi, 2020).

Só para dar alguns exemplos certamente parciais, o memory turn sobre a ditadura tem como caraterística não se limitar ao contexto brasileiro, mas se articular numa dimensão continental, latino-americana, com escritoras que são filhas da diáspora política da década plúmbea de 1970 (Paloma Vidal, Gabriela Aguerre, Carola Saavedra), e com o sucesso de A resistência, de Julián Fuks (2015), narrativa do irmão adotivo que leva o narrador a voltar para a Argentina das origens antes do exílio da família no Brasil, para entender o passado familiar e para escrever suas memórias. O livro do filho - diga-se de passagem - é lido pelos pais que não se identificam no enredo: a escrita, qualquer escrita do passado, sempre será marcada por desvios e incongruências. Mas, apesar dos limites da representação, o passado encontra, em romance como o de Julián Fuks, uma inscrição, a memória pode fluir de uma geração para outra.

O centro dessa tendência, aliás o que torna possível e substancia essa tendência memorialista preocupada com a transição de memórias, é representado pelo romance de Bernardo Kucinski, K Relato de uma busca (2011), e com seu apêndice metaliterário, Os visitantes (2016). Não se trata de "pós-memória", evidentemente: o autor e o romance vêm de um conhecimento direto da brutalidade autoritária, mas fundam um dispositivo de relação com o passado que poderá servir tanto para a salvação de memórias vivenciais, como para a transferência geracional de memórias traumáticas.

A situação, em Kucinski (2011), de fato, é oposta à estilização de uma relação filho/pai: a construção ficcional de um pai à procura da filha desaparecida política. Na codificação do uso da ficção, do fragmento, da fantasmagoria do mal, pelo exercício de transferência de memórias do passado, inscreve-se o seu valor paradigmático, no movimento de reconstrução do rosto do horror do passado autoritário, para a sua partilha com quem não o vivenciou. Na construção do campo da memória traumática, a obra de Kucinski proporciona um paradigma que serve e servirá para criar processos memoriais (ou "pós-memoriais") a partir de reusos literários de sobrevivências, que não abdicam de um forte sentimento ético em relação ao passado.

Um exemplo mais próximo dessa preocupação com a memória da ditadura militar e de suas vítimas, com foco na segunda geração, portanto, entrando idealmente no âmbito pós-memorial das sobrevivências, por assim dizer, é o romance recente, O corpo interminável, de Cláudia Lage (2019), que encena a trajetória de um filho de uma desaparecida que tenta procurar reconstruir, por rastros e indícios, a figura materna, num quadro social no entanto mais amplo, que não se reduz ao mundo da oposição política ao regime, mas a uma fatia mais ampla da sociedade brasileira (como, aliás, também em $K$ emerge com evidência), o que torna efetivamente $o$ período autoritário responsabilidade dos militares, mas também dos apoios profundos em várias esferas da sociedade civil. Como hoje se diria, na tentativa de uma construção seletiva e nostálgica daquele passado. 
As representações - na literatura, mas também em qualquer outro campo das artes - da segunda geração em relação à cena traumática são importantes porque não só contribuem pela tradução e pela tarefa do tradutor - para fundar o campo da compaixão (que possibilita a relação do testemunho) em torno dos traumas opacos do passado, mas também porque, pelas mitologias familiares que elaboram e projetam para fora, tornando-se comunicação, reinscrevem no espaço público a dimensão de uma memória outra que - como se disse - tem seu limite no seu caráter individual e privado, frequentemente, intransitivo. Ainda assim oferecem sobrevivências de um tempo acabado que se procura salvar. Funda-se assim uma comunidade que intersecta público e privado, uma comunidade memorial que pode salvar algum resto do passado. Finalmente, se esta configuração do horizonte das sobrevivências e do suplemento do gesto do tradutor/autor que dela se origina efetivamente funciona, a memória pública de uma experiência traumática se tornaria assim possível.

Não só, mas o impasse da transmissão/transferência da memória, assim simbolizada para as novas gerações, seria de certo modo superado através de uma pedagogia da reelaboração da história como trauma - não só reduzida em lembranças -, mas projetada politicamente no espaço público. A "pós-memória" assim reconfigurada, portanto, implicaria sempre uma relação pelo menos dupla, conectada pela finalidade das sobrevivências: é tradutória (também quando ocorre no plano estético) e se realiza pela mediação de um intérprete. Deste modo, se materializa a finalidade expressa por Benjamin na tarefa do tradutor: despertar no ponto de chegada da operação de tradução "o eco do original".

Isso contratualiza a compaixão própria do testemunho implicada pela transmissão da memória e, em simultâneo, dissemina imagens superstites, sobreviventes de uma outra memória que ressignifica, não melancolicamente, as perdas e os vácuos do passado.

Se assim for, refletir sobre os limites da "pós-memória", sobre as potências das "sobrevivências" do passado, ler o bordado do trauma penosamente urdido pelo silêncio da vítima e deixado como legado aos familiares, pode ser um ato politicamente ativo: inclusive para repensar na comunidade e nas multíplices violências identitárias e sociais a que frequentemente se recorre para resancionar a sua fundação.

Uma política de "sobrevivências", que reformula o conteúdo da transmissão da memória a partir de uma figuralidade residuária, hesitante, mas responsavelmente em contato com o passado, talvez contribua para salvar passados em risco, ainda que só precária e parcialmente. Uma memória que não é tautologia do tempo, mas é procura ou desejo - responsável, através de uma ética de reuso que coincide com um exercício da crítica - de comunicação, de comunidade de e com o passado.

\section{Referências}

AGAMBEN, Giorgio (1998). Quel che resta di Auschwitz. L'archivio e il testimone. Torino: Bollati Boringhieri.

AGAMBEN, Giorgio (2000). Il tempo che resta. Un commento alla lettera ai Romani. Torino: Bollati Boringhieri.

ASSMANN, Aleida (2002). Ricordare: Forme e mutamenti della memoria culturale. Tradução de Simona Paparelli. Bologna: Il Mulino.

BENJAMIN, Walter (1962). Il narratore. Considerazioni sull'opera di Nicola Leskov. In: BENJAMIN, Walter. Angelus novus. Saggi e frammenti. Tradução de Renato Solmi. Torino: Einaudi. p. 247-274.

BIDUSSA, David (2009). Dopo l'ultimo testimone. Torino: Einaudi.

DERRIDA, Jacques (1994). Spettri di Marx: stato del debito, lavoro del lutto e nuova Internazionale. Tradução de Gaetano Chiurazzi. Milano: Raffaello Cortina.

DIDI-HUBERMAN, Georges (2006). L'immagine insepolta. Aby Warburg la memoria dei fantasmi e la storia dell'arte. Tradução de A. Serra. Torino: Bollati Boringhieri. 
DIDI-HUBERMAN, Georges (2010). Come le lucciole: una politica delle sopravvivenze. Tradução de Chiara Tartarini. Torino: Bollati Boringhieri.

FERRONI, Giulio (1996). Dopo la fine: sulla condizione postuma della letteratura. Torino: Einaudi.

FINK, Ida (2002). Frammenti di tempo. Tradução de Laura Quercioli Mincer. Firenze: Giuntina.

FUKS, Julián (2015). A resistência. São Paulo: Companhia das Letras.

GATTI, Gabriel (2008). El detenido-desaparecido: narrativas posibles para uma catástrofe de la identidad. Montevideo: Ediciones Trilce.

GRAMMONT, Guiomar de (2015). Palavras cruzadas. Rio de Janeiro: Editora Rocco.

GRAMSCI, Antonio (1975). Quaderno 25 (XXIII) 1934: Ai margini della storia (storia dei gruppi sociali subalterni). In: GRAMSCI, Antonio. Quaderni del carcere. Torino: Einaudi. v. 3, p. 2277-2294.

HIRSCH, Marianne (1997). Family frames: photography, narrative and postmemory. Cambridge: Harvard University Press.

HIRSCH, Marianne (2006). Immagini che sopravvivono: le fotografie dell'Olocausto e la post-memoria. In: CATTARUZZA, Marina; FLORES, Marcello; SULLAM, Simon Levis (ed.) Storia della Shoah. La crisi della Europa, lo sterminio degli ebrei e la memoria del XX secolo. Torino: UTET. v. 3, p. 385-421.

HIRSCH, Marianne (2012). The generation of postmemory: writing and visual culture after the Holocaust. New York: Columbia University Press.

KUCINSKI, Bernardo (2011). K. Relato de uma busca. São Paulo: Expressão Popular.

KUCINSKI, Bernardo (2016). Os visitantes. São Paulo: Companhia das Letras.

LAGE, Cláudia (2019). O corpo interminável. Rio de Janeiro: Record.

LANDSBERG, Alison (2004). Prosthetic memory: the transformation of American remembrance in the age of mass culture. New York: Columbia University Press.

LEVI, Primo (1991). Prefazione. Rivistando i Lager, 6-7. Milano: Idea Books.

LISBOA, Adriana (2010). Azul-corvo. Rio de Janeiro: Editora Rocco.

PASOLINI, Pier Paolo (2020). Escritos corsários. Tradução de Maria Betânia Amoroso. São Paulo: Editora 34.

RUBENS PAIVA, Marcelo (1984). Feliz ano velho. 28. ed. São Paulo: Brasiliense.

SARLO, Beatriz (2007). Tempo passado: cultura da memória e guinada subjetiva. Tradução de Rosa Freire d'Aguiar. Belo Horizonte: Editora da UFMG; São Paulo: Companhia das Letras.

TRAVERSO, Enzo (2006). Il passato: istruzioni per l'uso. Storia, memoria, politica. Tradução de Gianfranco Morosato. Verona: Ombre Corte.

VECCHI, Roberto (2020). A impossível memória de Araguaia: um patrimônio sem memorial? In: OLIVEIRA, Rejane Pivetta de; THOMAZ, Paulo C. (ed.) Literatura e ditadura. Porto Alegre: Zouk. p. 45-58.

WAJCMAN, Gérard (1998). L'objet du siècle. Lagrasse: Verdier.

YOUNG, James E. (2000). At Memory's edge. After-images of the Holocaust in contemporary art and architecture. New Haven: Yale University Press. 